\title{
Grafologías mórficas en la ciudad hoy: I nvestigación, exploración y docencia en la terminal abierta de la imagen. Workshop Internacional 2005
}

\author{
Morphological graphologies inthe city \\ today: I nvestigation, exploration and \\ teaching in the open image terminal. \\ I nternational Workshop 2005
}

Miguel Vital e*

$<$ Resumen>

La ciudad, sus comportamientos físicos-sociales se transforman en la cultura contemporánea, los medios digitales y su relación con el factor humano toman nuevos derroteros, que desde el campo de la morfología urbana requiere de investigación exploratoria y transferencias docentes necesarias para la interpretación cognitiva y operacional de las grafologías heterológicas.

$<$ Abstract>

The city, its physical-social behaviours are transformed in the contemporary culture, digital media and its relationship with the human factor take new courses that, from the urban morphology field, require exploratory investigation and pedagogical transfers necessary for the cognitive and operational interpretation of the heterological graphologies.

-PALABRAS CLAVE

IMAGEN / METODOLOGías / DISEÑo / cIUDAD / PROYECTO

KKEY WORDS

IMAGE / METHODOLOGY / DESIGN / CITY / PROJECT

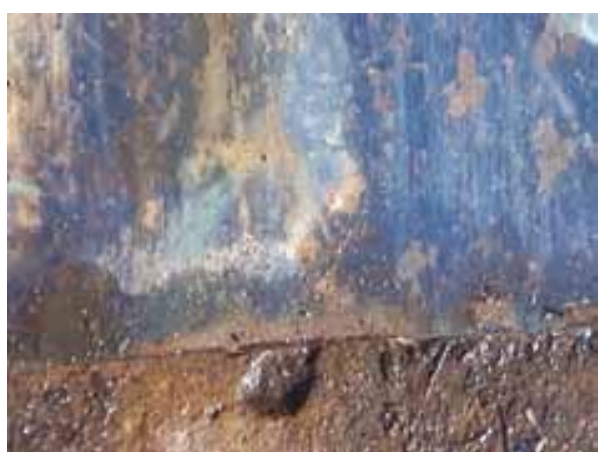

"Al hacer un balance, ¿qué es un pliegue? Un germen de forma. Pero, ¿qué es un germen sino un conjunto de pliegues? El pliegue es el elemento de la forma, el átomo de la forma sí, su clinamen. Pero, ¿qué es una forma? Respuesta: algo liso con pliegues».

Michel SeRRES ${ }^{1}$ 


\section{Presentación}

El presente trabajo esboza una doble finalidad, por un lado, propone un sintético recorrido por conceptos de investigaciones en las que participa el autor en el marco de los programas de investigación de la SeCyt, Universidad Nacional del Litoral, Santa Fe, Argentina, en relación con las distopías y heterologías observables en la condición cultural contemporánea.

Por otra parte, despliega prácticas docentes, que a modo de semióticas abiertas de producción, adoptan el formato de laboratorio morfológico de exploración urbana, centrado en la problemática de la textualidad de la imagen contemporánea y en la búsqueda de analíticas transdisciplinares que den cuenta de ciertos ejes de rotación, enunciantes de desplazamientos conceptuales en el diseño, ampliando su epistemología, hacia la proyectualidad. En tal sentido las producciones, metodologías proyectuales y campos experimentales que se abordan y ejemplifican, se cifraron en el Workshop internacional 2005 «Intervenciones en la Ciudad Contemporánea: zonas de obsolescencia y espacios públicos», llevado adelante en doble sede simultánea, en el marco del Taller Proyectual en Morfología Urbana (FADU-UNL) y disciplina optativa curricular (EESC-USP).

Los conceptos contenidos en este texto, atraviesan a modo de entrelíneas determinados axiomas proyectuales, poniendo en cuestión la mimesis de la representación como única categoría del pensamiento (proyectual por extensión) y a la vez la indisolubilidad de las certezas epistemológicas y metodológicas.

Si bien se advierte cierta vacancia de significaciones culturales plenas instituidas; ta cuestión, aceptando la posibilidad cierta como hipótesis, que la ciudad y el espacio público, son formas textuales capaces de ser leídas interpretadas como tramados emblemáticos, permiten ubicarnos en la perspectiva histórica, para comprender lo urbano como construcción corpórea significante de la esfera cultural.

Es necesario simultáneamente indagar las semióticas indiciales que expresan las enunciaciones de sentido hacia acontecimientos de intensidad pulsional. Tal cometido sustenta el rasgo exploratorio, conjetural y heurístico de las aristas por la que transitan los conceptos y operaciones que se esgrimen. Si lo convocante del encuentro de Sigradi 2006 es la problemática de los medios digitales y su encuentro con el factor humano, la temática nos ubica frente a uno de los desafíos más inquietantes para transitar la docencia universitaria de un tiempo a esta parte: la tensión producida entre saberes y operaciones desplegadas desde las didácticas activas presenciales y la indagación de nuevas competencias y posibilidades que ofrecen para docentes y discentes los inéditos formatos tecnoeducativos. Lejos del contraste opositivo entre tradición e innovación disciplinar-educativa, esta perspectiva expone reflexiones que necesariamente deban hacerse, transversalizando lo que se ha puesto en el centro y lo que se ha desplazado, en la comprensión que lo educativo-factor humano y las tecnologías, no son centros o bordes por sí, sino que como todo concepto que desde el espacio liso de la teoría presenta la figura cerrada de lo asertivo, se pliegan. Pliegue que se propone desde la cultura, cultura que estría los conceptos, produciendo formas urbanoculturales

\section{Enfoques epistémicos}

El carácter social, comunicacional y simbólico de la ciudad, residió hasta nuestros días en las correspondencias entre formas perceptuales, usos públicos y privados en sus dominios y la referencialidad textual habiéndose presentado lo urbano en su naturaleza de texto leído e interpretado desde una significación plena. La coetaneidad, presenta intersticios conceptuales en los espacios emblemáticos como en los lugares de la vida cotidiana de la ciudad, generando fluctuaciones en la hegemonía interpretativa. Las migraciones textuales, los desplazamientos de sentido, las temáticas y demandas inéditas, sustentan la investigación del espacio urbano, desde una mirada que explora los fenómenos indiciales, reavivando lo urbano como entidad grafológica: los modos de escribir en el texto ciudad. Experiencia rica de formas, marcas y señales sutiles, que esbozan desde imágenes y percepciones un repensar de las calidades latentes de urbanidad.

Si algo nos sorprende hoy por hoy, es sabernos inmersos en una cultura cuyo cartografiado puede resultar disonante a un método, esquiva a lo taxativo, alejada de una interpretación unívoca, necesitada de varias voces: la distopía y la diversidad, requieren de la anuencia de otros portulanos, diferentes a los que Deleuze advirtió en el origen del mar navegable, que tracen la posibilidad de sobrevolar y conceptualizar en la haecceidad indicial de los nuevos escenarios culturales plurilógicos. Entre otros indicadores, de la significación al sentido, es la brecha que se ha abierto en los desplazamientos del lenguaje a la imagen. De lo simbólico a lo indicial, en la hibridación analógico digital. Las pujas e intereses en tensión del ámbito social hacen que al espacio público discursivo homogéneo, consensuado y emblematizado, se le sobrepongan a la vez narrativas que, presentizan en la imagen, «señal débil» del lenguaje, territorialidades cognitivas que reposicionan saberes, estrategias y prácticas educativas. Transcursos y tránsitos, trazas de un estadio cultural que no se refleja únicamente en los paradigmas.

Desde los roles investigativos y académicos, se instalan nuevos mapas epistémicos, en los que las espacialidades urbanas, despliegan imágenes tejidas transdisciplinarmente, constituyendo verdaderas terminales abiertas en la hibridación analógico-digital. Desde esta perspectiva, como arquitectos, docentes e investigadores se plantea la necesidad de formular, debatir y otorgar herramientas conceptuales e instrumentales que permitan comprender e intervenir situaciones morfológicas espaciales concretas condicionadas por su pertenencia a una dimensión heterológica, antes que estrictamente arquitectónica, referidas a situaciones urbanas, que entre otros indicadores, por su escala paisajística, condición pública, nivel de antropomorfización, hibridez morfológica, precariedad de usos, imágenes difusivas y discontinuas, requieren de una reflexión para descifrar lo propio concreto y a la vez los posibles universos referenciales instalados hoy por hoy culturalmente. Desde los inicios de las investigaciones proyectuales sobre la ciudad contemporánea, denominamos a estos derroteros, «andamiajes grafológicos», ¿qué se pretende sostener...?, una construcción de sentido para la dimensión creativa e interpretativa del espacio urbano hoy.

\section{Antecedentes investigativos y académicos}

Textos, hipertextos, lenguaje, discursos, metadiscursos, narraciones... espacios, imágenes, formas, se presentan como fenomenologías que se indagan exploratoriamente desde heurísticas no lineales, en proyectos de investigación multidisciplinares y sus extensiones académicas en los que viene participando el autor, donde, aceptando del lector una capacidad planar de síntesis, se abordan tres ejes cognitivos: Ios pasajes de la imagen como texto discursivo cultural a la condición de textualidad transcursiva, los desplazamientos en el diseño de formas urbanas instituidas a los agenciamientos de la proyectualidad estética performativa y los saberes que ponen en debate la convencionalización de significados y prácticas 
en el espacio público. Tópicos que serán sobrevolados, con la posibilidad de extensión que permite un artículo, en la confianza de abri un espacio de opinión, continuidad y contrastes de miradas, aportando valga la homofonía con el evento, más factor humano.

Desde estos enfoques y operaciones de indagación morfológica proyectual, copresentes en el fenómeno local-global de la ciudad, se han desarrollado, como antecedencias investigativas y académicas, los cursos «Imagen y Cultura Hoy» y «Paisaje y Espacio Público» mediante la Red a Distancia Multicampus de la UNL, contrastando experiencias académicas y la construcción de los imaginarios colectivos y personales en distintas ciudades y localidades argentinas, donde la imagen urbana tensiona la glocalización finisecular. También en educación a distancia se han propuesto módulos de Morfología en Diseño y en Artes Visuales FADU-UNL. Recientemente se ha participado de la convocatoria Sense of the City-CCA (Canadian Centre for Architecture), Canadá y se ha dictado la reedición del Seminario «Imagen y Cultura Hoy» en la Universidad de Valparaíso, Chile.

El Laboratorio de Exploraciones Formales 2003-2004, actividad extracurricular presencial, hoy Taller Proyectual en Morfología Urbana, materia optativa curricular de la FADU-UNL, constituyen los planos de referencia donde se han puesto en acción proyectual morfológica los conceptos y prácticas que serán explicitados.

Actualmente se encuentran en desarrollo dos convenios de investigación y cooperación académica conjunta, uno con la Universidad de Chile y otro con la Universidad de San Pablo-Brasil a los fines de llevar adelante estudios en ciudades medias latinoamericanas, donde se indagan las relaciones entre los enfoques técnicos sistémicos en sobreposición con las miradas estéticas morfológicas de la contingencia coetánea. La oportunidad es propicia para mencionar al Prof. Alberto Gurovich, coordinador académico del convenio por la FAU-Universidad de Chile y en esta mención el reconocimiento también a la Revista De Arquitectura, quienes invitaran al autor a participar en carácter de profesor visitante del Foro de titulación de arquitectos en la Universidad de Chile. Problemática abordada desde diversas angularidades académicas en el número doce de la publicación, en una mañana en que Santiago parecía impenetrable desde la Estación Pajaritos a la Confitería Torres, valió la disputa con el tráfico metropolitano a la luz de lo que allí se debatió.
A partir de los mencionados antecedentes y a modo de corolario de las exposiciones de Sigradi 2004 y 2005, se presentan los últimos segmentos investigativos sobre morfología urbana, contrastando mapas conceptuales avanzados y estrategias académicas de implementación. La experiencia del Taller Proyectual en Morfología Urbana y el Workshop mencionado con Brasil sobre intervenciones en la ciudad contemporánea, centrarán la puesta de imágenes y producciones proyectuales.

\section{Objetivos relevantes}

Presentar resultados proyectuales académicos de intervenciones urbanas, ejerciendo relecturas cognitivas, desde conceptos, variables y categorías, con miras a la resignificación morfológica y de actividades de sectores en obsolescencia, nuevos imaginarios del espacio público e inéditas reapropiaciones espaciales en diferentes situaciones y condiciones de ciudad. Contrastar para el caso de la ciudad de Santa Fe, las diferentes lógicas de intervención, sea en la ciudad central histórica del espacio matrizado por la presencia de lugares con apropiación e identidad, retícula, plazas y parques o en la sobrepuesta, ciudad emergente, difusiva, donde migran los paradigmas de la centralidad. Ciudad que comunica sus narrativas, en imágenes fugaces, percepciones débiles, vacíos extensivos, donde naturaleza y artificio se hibridan. Ciudad con localizaciones arquitectónicas discontinuas en corredores urbanos, trazando un incipiente proceso de metropolización, donde el lugar no parece ser la clave interpretativa y lo proyectual se presenta como una construcción de un nuevo sentido.

Poner en reconsideración los fenómenos urbanos, desde los inferidos por la construcción del topos, lugar a los que aparentan advenir de situaciones más triviales o ubicuas, capaces de generar información para intervenir creativamente en las complejas textualidades de la ciudad hoy por hoy. En tal sentido, mediante el desmontaje de la textualidad de imágenes y ambientes, se despliegan relaciones transperceptuales, según estructuraciones, acumulaciones y sobreposiciones conceptuales y contextuales, buscando otro sentido en lo urbano. Proponer procesos de morfogénesis transpositivos y enunciativos, donde proyectar y actuar se reúnen como factor humano en proyeactuar, ámbito sensitivo que enlaza la potencialidad cognitiva del emplazamiento conceptual y la sensibilidad transperceptual del emplazamiento situacional.

\section{De la investigación al formato académico docente: Taller Proyectual en Morfología Urbana y Workshop 2005}

El taller se despliega a modo de aboratorio donde se ensayan problemáticas, metodologías, modos de abordar y comunica procesos exploratorios de constitución formal no habituales en las currículas establecidas. En tal sentido se ponen sensiblemente en reconsideración la cognición y producción de formas en las disciplinas proyectuales a partir de operaciones de transferencia de conceptos, interrogando la validación relacional entre formas y significaciones en la cultura de nuestros días, reflexionando mediante la discursividad crítica, textos significativos de autores y docentes referidos a las problemáticas de interfases morfológicas, los fenómenos de mediatización entre formas y manipulación conceptual de imágenes, e estado de situación de la entidad perceptual y representacional del objeto cultural, entre otros itinerarios que dan cuenta de revisiones epistemológicas.

En la dinámica didáctica con los alumnos, se requiere desarrollar acciones proyectuales en las diferentes formas territoriales de la ciudad hoy por hoy, en las cuales se advierten tensiones entre dominios, legalidades, usos y prácticas urbanas. Situaciones que requieren de la resignificación de conocimientos y experiencias en la dimensión morfológica urbana, en torno de las configuraciones del paisaje, la estética de la ciudad, los patrones de comportamiento social y las nuevas demandas y espacializaciones de los lugares abiertos ciudadanos.

\section{Matriz epistemológica del TPMU}

La matriz exploratoria consiste en transitar los procesos Morfológicos Heurísticos, con énfasis en los enunciativos, centrados en analíticas de imágenes urbanas paisajísticas de emplazamientos conceptuales y situacionales. En este territorio se mapean operaciones estético-semióticas por métodos analógicos y digitales, desde lógicas que enuncian un sentido, antes que adherir a una significación establecida, operando sobre un sistema textual de continuidades tanto como de las discontinuidades del acontecimiento expresado. 


\section{Problemáticas centrales}

Las problemáticas centrales se instalan a partir de hipótesis investigativas, las que atraviesan los siguientes tópicos presentes en las disciplinas proyectuales:

- Percepción - Neopercepción

- Lenguaje - Imagen

- Textos - Textualidades

- Discursos - Narrativas

- Proyecto - Proyectualidad

Las búsquedas de taller sobrevuelan los espacios creativos de producciones formales alternativas, es los que formalizar requiere construir una conceptualización enunciativa. La oportunidad posibilita internarse en la exploración de estéticas de diseño no lineales, dismétricas a la tradición kantiana.

\section{Mapa de exploración}

Se propone deconstruir el concepto de método, a través de una relectura filoepistemológica de sus orígenes, donde odós y methá, es decir camino y fin no constituían una unidad de sentido, reuniéndose en el pensamiento científico, instaurando el método discursivo, donde la lógica textual puede discernir por fuera de los acontecimientos.

En la experiencia del Taller Proyectual en Morfología Urbana se propone la transcursividad, el operador atraviesa los conceptos como actuante del acontecimiento y producción formal.

\section{Conceptos teóricos abordados}

A partir de emplazamientos situacionales y conceptuales propuestos por la cátedra, se formuló un mapa teórico de exploración en base a 2 conceptos: percepción e imagen, indagando las diferencias entre impresiones de la imagen y significaciones perceptuales. A la vez los dos conceptos fueron divididos en 3 variables: Estímulo, Tiempo y Estética, en la búsqueda de la mutabilidad o desplazamiento de la fijeza perceptiva, en relación con la indicialidad, autorreferencia, capacidad de información, que es capaz de obtenerse en la manipulación de registros y mediatizaciones. Finalmente las tres variables fueron atravesadas por 2 categorías, para analizar estímulos por densidad e intensidad, tiempo sincrónico e instantáneo y estética discursiva o transcursiva, según los relatos formales se desplazaran entre narraciones o enunciaciones.
Material expuesto en formato video / Muestra Multimedial Sigradi

Propuesta 1 - cursantes:

Valarolo / Luviano / Luviano / Quarati
Propuesta: Partiendo de un emplazamiento conceptual que trama fragmentos cinematográficos, pregnancias gestálticas y exploraciones de movimientos del emplazamiento situacional, los autores ponen en valor espacial un área de vacancia en ciudad emergente. A modo de paratexto,
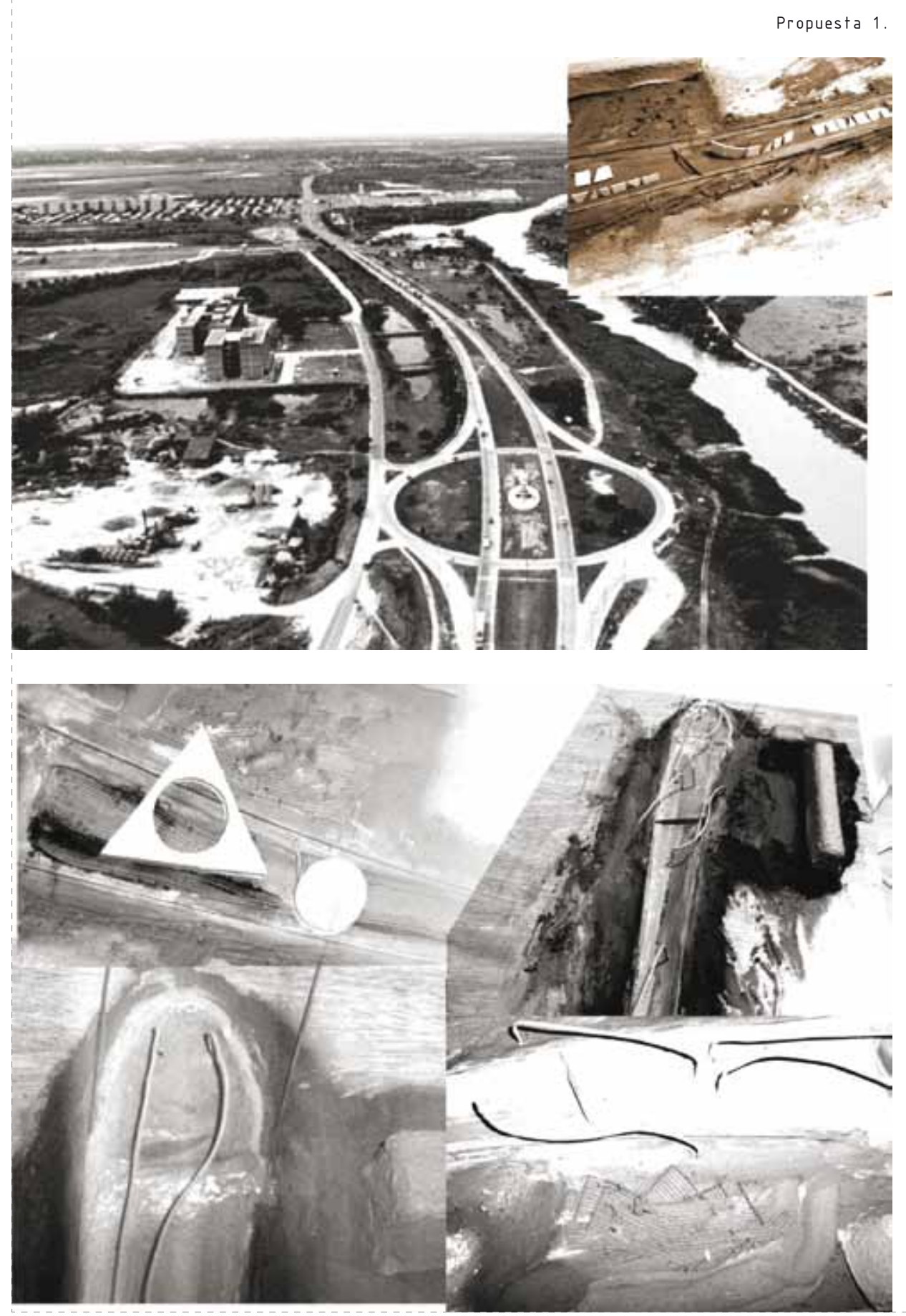
la exploración mediante modelización de maqueta analógica y registros digitales, permite indagar la relación tiempo-movimiento, el objeto formal puede ser explorado visualmente por las imágenes de su exterioridad, como ser infiltrado por una secuencia interactiva interior, donde el observador percibe el contraste de la activación de piezas textiles móviles que mutan la formalización y lo constante formal generado por equipamientos urbanos fijos.

Sentido: Generar espacios para el contacto, morfologías para incitar a la exploración, clausurando la unifuncionalidad
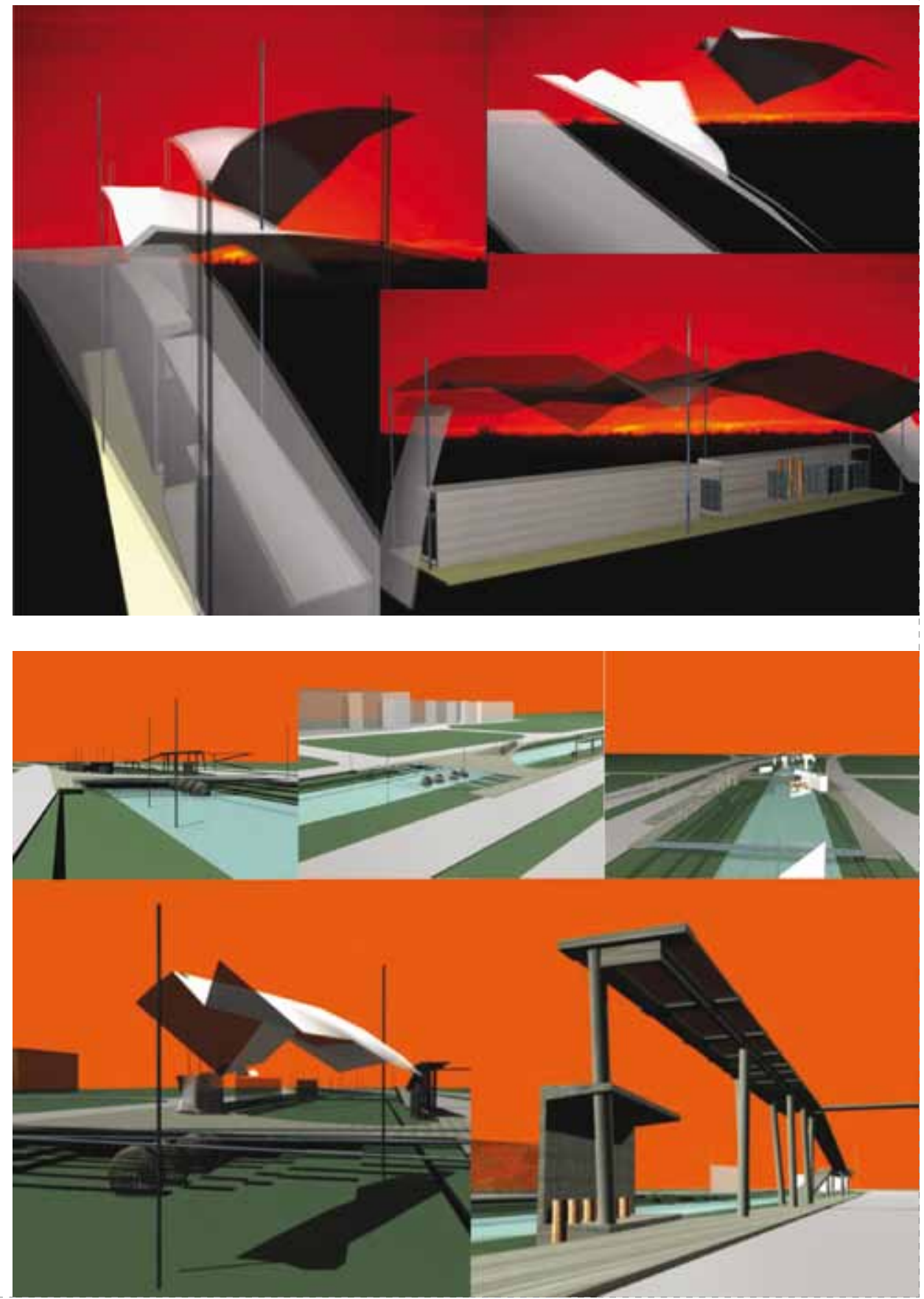

del espacio exterior, la incorporación de objetos desmontables y la libertad de usos, dan sentido a una narrativa contrastante entre lo efímero y lo permanente. El pasaje de un sitio de extrema indeterminación, mediante el rescate de las huellas del lugar, recrea una condición de paisaje dismétrico.

Exploración: Manipulación del modelado analógico con imágenes en video digital, mediante la metodología de verbalización de una situación, sobreponiendo los límites perceptivos de los estímulos visuales. Superposición y entretejido de estructuraciones, detención del tiempo mediante la resistencia a lo instantáneo, descubrimiento de la diversidad con énfasis en la captación de la condición eventual, en que las micronarraciones sensibilizan una situación, recreándose la artificialidad textual estética del montaje.

Búsqueda: Desplazamiento de la mirada habitual del espacio, migrando conceptos hacia campos neoperceptuales que densifican el tiempo instantáneo de la narrativa: simplicidad mutable, pregnancia efímera, semejanza variable, continuidad fragmentada-transitoria y espacio heterogéneo y superpuesto.

\section{Propuesta 2 - cursantes: Bordas/ Busaniche / Hernández / Sánchez}

Propuesta: Los autores a partir de poner en acción mecanismos neoperceptuales, trazan búsquedas alternativas a los estadios perceptuales; el trabajo opera como agenciamiento de los expresables de la imagen urbana, sobre la base de registros diurnos y nocturnos de un área paisajística ribereña. Se introduce el medio digital mediante la sistematización formal de acumulaciones y repeticiones en imágenes extraídas de la captura espontánea de situaciones del sitio.

Sentido: Construir la nueva narrativa mediante los elementos formales detectados en los videos registros: luces y sombras del espacio. El sentido se produce en la textualidad transcodificada de la información situacional.

Exploración: Investigación de semiótica indicial sistematizada en cuatro fases: 1 ) detección de los parámetros de luz del pixelado de imagen testigo y exploración del relieve topográfico pixelar; 2) obtención de patrones de luz; 3) abstracción de los mapas lumínicos; 4) operación enunciativa proposicional: allí donde el intelecto no ha generado una nueva construcción de 

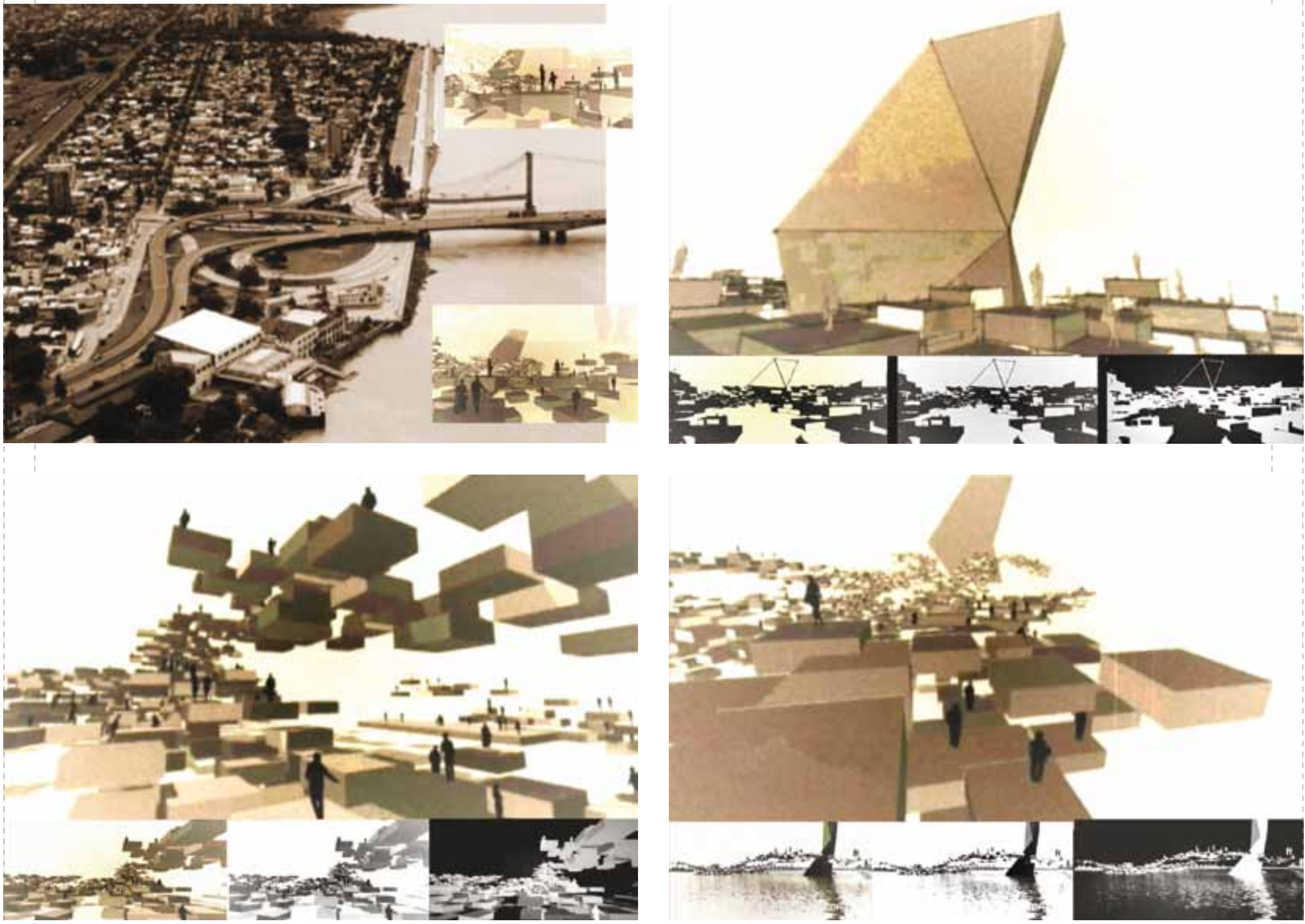

Propuesta 2

sentido, es entonces donde surge el pliegue o acontecimiento, la intensidad se instala como interferencia en la línea forma-significado.

Búsqueda: Textualidad fundada en la transversalidad de las propiedades físicas de la luz y las poéticas espaciales urbanas sugeridas por los procesos forma-imagen. Los puntos-cuerpos sugieren una estructura microconfigurativa, tectónica y sintaxis espacial devienen transcursivamente. Si la luz es materia, la penumbra es la negación de lo tangible, ante la ausencia, ¿Cómo contener la luz?, si su ausencia es el movimiento, la luz liberada genera una realidad dinámica entonces la luz contenida produce una realidad pixelada.

\section{Propuesta 3 - cursantes:}

Fiегго / Sincovich

Propuesta: Rescate arqueológico de la espacialidad vectorial del puerto de la ciudad y reequipamiento de sector urbano deprimido semánticamente, disfuncional. Propuesta de refuncionalización y resignificación explorand actualizaciones discursivas, mediante barras lineales de funciones abiertas que actúan por contigüidad sintáctica formal; el área se arquitecturiza como escena urbana.
Sentido: Informar la forma mediante manipulación de modelo analógico, posterior exploración lumínica y fotocromática, donde el medio digital reconstruye un sobretexto que conecta el área portuaria con la ciudad de borde, mediante un espacio exterior que afecta el sentido convencional de plaza.

Exploración: Sobre la base del modelado por maqueta básica, se ponen en revisión las formas topológicas del espacio externo, mediante una estética topográfica de pliegues, hendiduras e intersticios denotados por los estudios de radiación lumínica nocturna; el aporte de fotografiado y manipulación digital permite indagar el formante visual luz-color. 

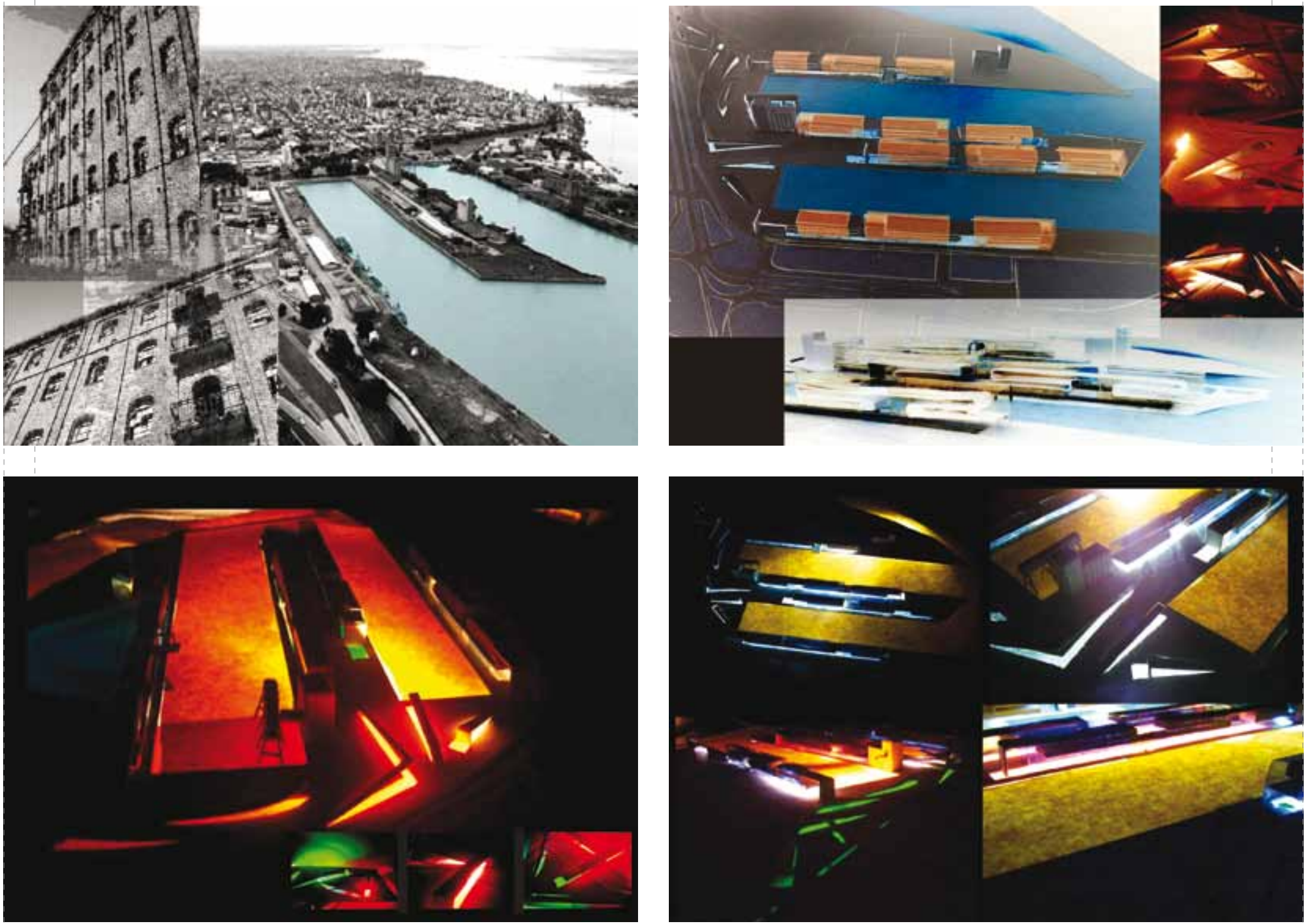

Propuesta 3

Búsqueda: Construir una espacialidad fuertemente centrada en los estímulos visotáctiles, reproponiendo desde las morfogénesis gestálticas de pregnancia; en tal sentido la percepción del sitio, su identidad figural nocturna, la plaza de los suelos-pliegues, conforman un sobrerrelato morfológico de llegada, marcado por la proyeactuación del proceso.
Propuesta 4 - cursantes: Retamar / Santiago / Grinovero

Propuesta: Operación formal de reciclaje y resignificación de un conjunto edilicio, ex molino harinero y espacio exterior contiguo subocupado para estacionamientos; la articulación interna-externa se genera mediante un espacio abierto que propone la funcionalización escultórica de los objetos formales involucrados, un paseo homenaje al arte y su fruición pública urbana.
Sentido: Confrontar el emplazamiento situacional central y físicamente definido de la intervención, con el emplazamiento conceptual enriquecido por los múltiples roces que se producen entre acciones diversas en un tiempo instantáneo, no lineal, dando cuentas de espacialidades flexibles, significaciones abiertas. Los acontecimientos así planteados, originan capas en vecindad mutua, donde la intensidad se produce en el contacto de los pliegues. 


\section{N 0}
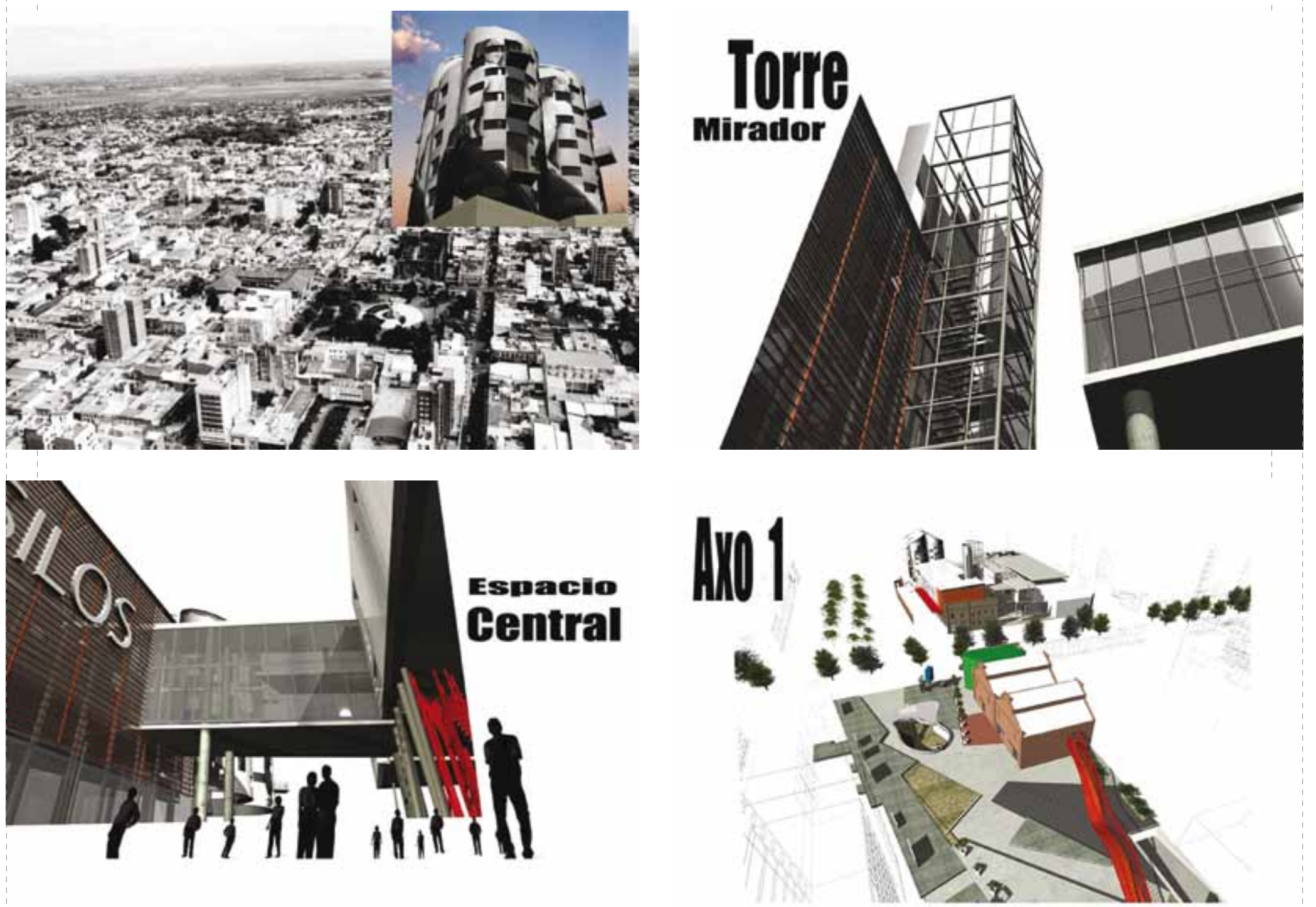

Propuesta 4

Exploración: Experimentación con la metodología de las verbalizaciones de un sitio, para la concepción espacial que se busca proponer; las capas de acontecimiento del espacio-pliegue determinan diversos significantes, por lo que a un determinado signo no corresponde un solo significante, sino una multiplicidad pansémica. La experiencia estética se produce con máxima heterogeneidad y de manera multifacética.
Búsqueda: Interpretación formal propuesta anclando tres conceptos: contemporaneidad, acumulación y acontecimiento, dónde el tiempo actúa como una explosión de sucesos en una diversidad heterológica, convirtiendo la experiencia estética de la arquitectura en acontecimiento-suceso. 


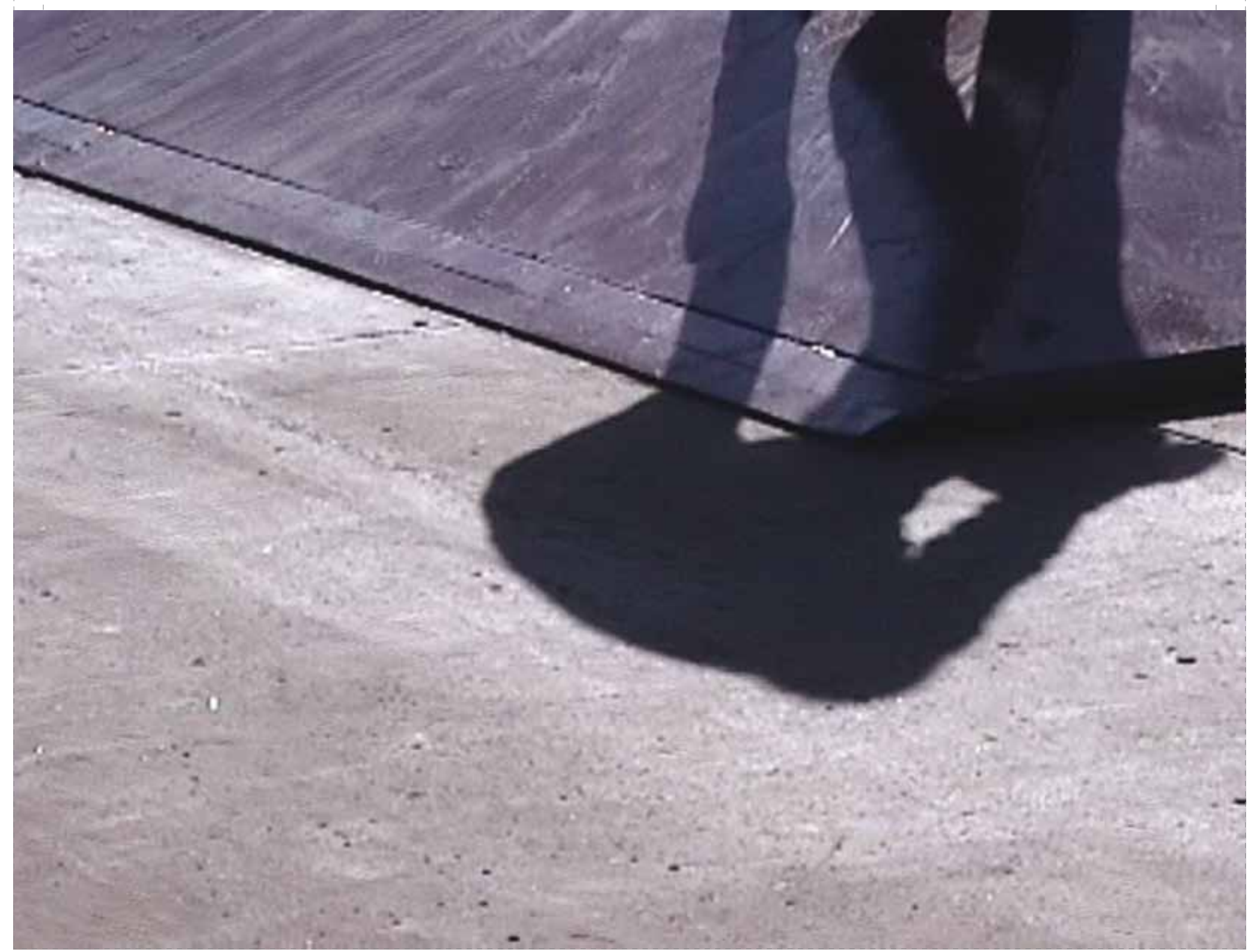

«.... Leibniz llamaba antitypia a la resistencia invencible o relativamente elástica de los sólidos y este término significaba, además, la propiedad que nos permite escribir sobre ellos: estables, fijos, es decir susceptibles de ser inscritos -mientras que nos resistimos a sumergirnos entre los líquidos, lo acuático y lo vaporoso-vago, confuso, turbio, decimos tontamente de un pensamiento despreciado-, reino fluido en el que las distancias cambian y fluctúan, en el cual, la escritura se borra y las medidas se pierden».

Michel SeRRes ${ }^{2}$ 